\title{
Antihypercholesterolemic Effects of Mushroom, Chrysin, Curcumin and Omega-3 in Experimental Hypercholesterolemic Rats
}

\author{
TAMER AHMED ISMAIL ${ }^{1,2, *}$, MOHAMED MOHAMED SOLIMAN ${ }^{1,3}$, MOHAMED ABDO NASSAN $^{4}$, \\ DALIA IBRAHIM MOHAMED ${ }^{5}$
}

\author{
${ }^{1}$ Medical Laboratory Department, Faculty of Applied Medical Sciences, Turabah, Taif University, Saudi Arabia \\ ${ }^{2}$ Department of Physiology, Faculty of Veterinary Medicine, Zagazig University, Egypt \\ ${ }^{3}$ Department of Biochemistry, Faculty of Veterinary Medicine, Benha University, Egypt \\ ${ }^{4}$ Department of Pathology, Faculty of Veterinary Medicine, Zagazig University, Egypt \\ ${ }^{5}$ Department of Biochemistry, Animal Health Research Institute, Zagazig Branch, Egypt \\ *Corresponding author: tamersml77@yahoo.com
}

Received December 19, 2014; Revised January 29, 2015; Accepted February 01, 2015

\begin{abstract}
Hypercholesterolemia and hypertriglyceridemia are major risk factors that accelerate the incidence of atherosclerosis and coronary artery diseases. Therefore, the present study was conducted to evaluate the hypolipidemic effect of widely known traditional medicinal herbs and omega-3 FA in experimental hypercholesterolemia induced by Triton WR-1339. Experimental hypercholesterolemic rats were administered mushroom, chrysin, curcumin and omega-3 for 2 weeks. Hypercholesterolemic rats showed an increase in serum levels of lipid profiles and hepatic enzymes. Hypercholesterolemic rats showed an increase in malondialdehyde (MDA) levels and a decrease in both serum levels and mRNA expression of catalase, superoxide dismutase (SOD) and glutathione reducatse. Moreover, hypercholesterolemic rats showed hepatic down regulation in the expression of genes related to fatty acids oxidation such as acyl CoA oxidase (ACO) and synthetase (ACS), together with carnityl palmityl transferase-1 (CPT-1) and peroxisome proliferator activator receptor- $\alpha$ (PPAR- $\alpha$ ). Administration of mushroom, chrysin, curcumin and omega-3 to hypercholesterolemic rats for 2 weeks up-regulated significantly the down regulated genes. In contrast, expression of genes related to fatty acids biosynthesis and cholesterol metabolism were increased in hypercholesterolemic rats compared to control group. Herbal medications and omega-3 administration down regulated genes of fatty acids biosynthesis and cholesterol metabolism to normal expression. At cellular levels, hyperlipidemia induced fatty droplets accumulation, necrosis and presence of apoptotic hepatocytes together with leukocytic infiltration in necrotic area that are ameliorated and normalized after administration of herbs and omega-3. In conclusion, the current findings indicated that flavonoids (mushroom, chrysin, curcumin) and omega-3 possess antihypercholesterolemic effects at biochemical, molecular and histopathological levels and are useful in treatment of hypercholesterolemia with lower side effects compared with synthetic hypolipidemic drugs.
\end{abstract}

Keywords: hypercholesterolemia, curcumin, mushroom, chrysin, omega-3, gene expression

Cite This Article: TAMER AHMED ISMAIL, MOHAMED MOHAMED SOLIMAN, MOHAMED ABDO NASSAN, and DALIA IBRAHIM MOHAMED, "Antihypercholesterolemic Effects of Mushroom, Chrysin, Curcumin and Omega-3 in Experimental Hypercholesterolemic Rats.” Journal of Food and Nutrition Research, vol. 3, no. 2 (2015): 77-87. doi: 10.12691/jfnr-3-2-1.

\section{Introduction}

Metabolic syndrome, a cluster of metabolic abnormalities, such as hyperlipidemia, diabetes mellitus, and hypertension, is a widespread and increasingly prevalent disease in industrialized countries and contributes to the increase in cardiovascular morbidity and mortality [1]. Hypercholesterolemia is one of the greatest risk factors contributing to prevalence and severity of coronary heart diseases [2]. The modern lifestyle, with a high fat diet and little physical activity, significantly contributes to the incidence of hypercholesterolemia and cardiovascular diseases [3]. Alteration in oxidative stress induced by reactive oxygen species (ROS) and impairments of the antioxidant system play a critical role in the pathogenesis of hypercholesterolemia and subsequent cardiovascular diseases [4,5]. Liver is the organ essential for the maintenance of systemic lipid homeostasis, and easily susceptible to damage by ROS [6] It has been shown that hyperlipidemia reduces the hepatic antioxidant defense system [7].

Although numerous synthetic lipid-lowering drugs, such as fibrates, statins, and bile acid sequestrates, have been developed to combat hyperlipidemia, management of this condition without accompanying drug side effects still poses a challenge [8]. The usage of synthetic drugs leads 
to hyperuricemia, diarrhea, nausea, myositis, gastric irritation, flushing, dry skin and abnormal liver and kidney function [9]. During the last decade, an increase in the use of medicinal plants and herbal medicine has been observed all over the world [2]. Medical plants are safe for health without side effects, encouraging patients to make it the first line for treatment.

Mushrooms are well known for their medicinal properties and have been widely used in traditional medicine. Mushrooms are highly nutritive plants as they contain good quality proteins, vitamins and minerals [10]. The oyster mushroom (Pleurotus ostreatus) contains many biologically active flavonoids, phenolic components, and carotenoids [11]. Edible mushrooms are the ideal materials for the dietetic prevention of atherosclerosis due to its high content of fiber, proteins, microelements, and low fat content [12]. Mushroom prevented weight gain in the mice and may be valuable in the formulation of adjuvant therapy for obesity [13]. More recently Jegadeesh et al stated that mushroom has greater significance in prevention of hyperlipidemia and cardiovascular disease [14]. On the same line, chrysin (5,7-dihydroxyflavone) is a natural flavonoids present in many plant extracts, honey and propolis $[15,16]$. Chrysin has anti-inflammatory and antioxidant properties, and is used as a dietary supplement [17].

Like mushroom, curcumin has become one of the most intensively investigated bioactive non-flavonoids extracted from turmeric, which is extensively used as a curry powder, spice and yellow pigment. Curcumin protects against the pathologic effects of obesity and related metabolic disorders [18]. Curcumin is known for its antiinflammatory, anticarcinogenesis, antiobesity, antiangiogenesis and antioxidant activities [19]. It protects against oxidative damage of liver induced by arsine [20]. As curcumin has a favorable effect in combating obesity-related disorders [21]. Another widely known is omega-3, many reports have confirmed the beneficial effects of marine derived omega-3 polyunsaturated fatty acids (PUFAs) in treatment of cardiovascular diseases [22]. Omega-3 has shown to reduce the incidence and mortality of cardiovascular diseases [23] and prevention and /or treatment of obesity and metabolic syndrome [24]. Moreover, omega-3 has the ability to improve insulin sensitivity and glucose homeostasis in rodents [25].

In the current study, we evaluated the antihypercholesterolemic effects of some widely common herbal plants used in traditional folk medicine and omega3 in an experimental animal model of hypercholesterolemia induced by Triton WR-1339.

\section{Materials and Methods}

\subsection{Materials}

Male Wistar rats were purchased from King Fahd Institute for Scientific Research, King AbdelAziz University, Saudi Arabia. Triton WR-1339 and chrysin were from Sigma Aldrich, CO, USA. Curcumin and mushroom were from Taif markets and were identified by specialists. Simvastatin and omega-3 were bought from Pharco Company, Jeddah, Saudi Arabia. Biochemical kits for kidney, liver and lipids profiles were from Clini Lab,
Cairo, Egypt. Solvents and related materials were from ADWIA pharmaceutical company, Egypt.

\subsection{Animals and Experimental Procedure}

Forty two Male Wistar rats, 6 weeks old, weighting (150-200 g) were housed under conditions of controlled temperature $\left(25 \pm 2^{\circ} \mathrm{C}\right)$ with a $12 \mathrm{~h} / 12 \mathrm{~h}$ day-night cycle in Medical Laboratory Department, College of Applied Medical Science, Turabah, Taif University. Animals gained free access to food and water ad libitum. All procedures were approved by the Animal Care Committee of Taif University for the project \#3103 /1435/1.

\subsubsection{Induction of Hypercholesterolemia in Wistar Rats}

Hypercholesterolemia was induced experimentally in 12 h-fasted rats by a single intraperitoneal injection of Triton WR-1339 (300 mg/kg body weight, b.wt), dissolved in $0.89 \%$ saline. Twenty four hours after administration of Triton WR-1339, rats exhibited elevated serum levels of total cholesterol and triglycerides, these rats were seemed to be hypercholesterolemic and used for further investigation and treatment [26].

\subsubsection{Preparation of Mushroom Extract}

Freshly harvested mushrooms (mushroom P. ostreatus) were shade-dried and then finely powdered. Five grams of the powder was extracted with $100 \mathrm{ml}$ of $95 \%$ ethanol using a Soxhlet apparatus. Mushroom extracts were then filtered through Whatman filter paper (no. 1). The solvent was evaporated under reduced pressure at $45^{\circ} \mathrm{C}$ by using a rotary evaporator for elimination of ethanol, and the dried extract was stored at $4^{\circ} \mathrm{C}$ until further use [27].

\subsubsection{Experimental Design}

The experimental rats were divided into seven groups (6 rats per group). Control group; didn't receive any medication and gained free access to food and water and served as negative control. Hypercholesterolemic group; injected Triton single dose at the beginning and maintained as a positive control without any action for 14 days. The remaining five groups were hypercholesterolemic and received following treatments. Simvastatin group; received orally simvastatin in a dose of $10 \mathrm{mg} / \mathrm{kg}$ b.wt. /day in aqueous suspension for 14 days [28]. Mushroom extract administered group (500 mg/kg b.wt. / day) where mushroom was given orally for 14 days [27]. Chrysin administered rats in a dose of $200 \mathrm{mg} / \mathrm{kg}$ b.wt. / day in $0.5 \%$ dimethyl sulfoxide (DMSO) orally for 14 days [27]. Curcumin administered rats in a dose of $400 \mathrm{mg} / \mathrm{kg}$ b.wt. / day dissolved in hazelnut oil orally for 14 days [29]. Omega-3 administered rats; omega -3 was given orally in a dose of $30 \mathrm{mg} / 100 \mathrm{gm}$ b.wt. / day for 14 days [30]. All administrations were administered orally by gastric intubation once daily for 2 weeks at fixed time. Blood samples and tissues were collected from all experimental rats on day 14 after overnight fasting by decapitation after diethyl ether inhalation. Serum was separated for biochemical and antioxidants measurement. Liver samples were preserved in $10 \%$ buffered neutral formalin for histopathological examination. Small pieces around $50 \mathrm{mg}$ were taken under aseptic conditions and preserved in 
TriZol reagent under $-80^{\circ} \mathrm{C}$ for RNA extraction and gene expression.

\subsection{Biochemical Measurements}

Serum triglycerides (TG), total cholesterol (TC), HDL, creatinine, urea, GPT and GOT were measured spectrophotometrically using specific commercial kits (HUMAN Gesellschaft fur Biochemica und Diagnosticam $\mathrm{bH}$, Wiesbaden, Germany) according to manufacturer instructions. Malondialdehyde (MDA), catalase, superoxide dismutase (SOD) and glutathione reductase were measured using ELISA kits based on the manufacturer's instruction manual from Biodiagnostic company, Dokki, Giza, Egypt.

\subsection{RNA Extraction and cDNA Synthesis}

Total RNA was extracted from liver tissue samples (approximately $100 \mathrm{mg}$ per sample) of experimental rats. Liver samples were flash frozen in liquid nitrogen and subsequently stored at $-70^{\circ} \mathrm{C}$ in $1 \mathrm{ml}$ Trizol (QIAGEN Inc., Valencia, CA). Frozen samples were homogenized using a Polytron 300 D homogenizer (Brinkman Instruments, Westbury, NY). Then, $0.3 \mathrm{ml}$ chloroform was added to the homogenate. The mixtures were shaken for 30 seconds followed by centrifugation at $4^{\circ} \mathrm{C}$ and $16,400 \times \mathrm{g}$ for 15 min. The supernatant was transferred to a new set of tubes, and an equal volume of isopropanol was added to the samples, shacked for 15 seconds and centrifuged at $4{ }^{\circ} \mathrm{C}$ and $16,400 \times \mathrm{g}$ for $15 \mathrm{~min}$. The RNA pellets were washed with $70 \%$ ethanol, briefly dries up, and then dissolved in Diethylpyrocarbonate (DEPC) water. RNA concentration and purity were determined spectrophotometrically at 260 $\mathrm{nm}$. The RNA integrity was confirmed in $1.5 \%$ agarose stained with ethidium bromide. The ratio of the 260/280 optical density of all RNA samples was 1.7-1.9.

For cDNA synthesis, mixture of $3 \mu \mathrm{g}$ total RNA and 0.5 ng oligo dT primer (Qiagen Valencia, CA, USA) in a total volume of $11 \mu \mathrm{l}$ sterilized DEPC water was incubated in the Bio-Rad $\mathrm{T} 100^{\mathrm{TM}}$ Thermal cycle at $65^{\circ} \mathrm{C}$ for $10 \mathrm{~min}$ for denaturation. Then, $2 \mu \mathrm{l}$ of $10 \mathrm{X}$ RT-buffer, $2 \mu \mathrm{l}$ of $10 \mathrm{mM}$ dNTPs and $100 \mathrm{U}$ Moloney Murine Leukemia Virus (M-MuLV) Reverse Transcriptase (SibEnzyme Ltd. Ak, Novosibirsk, Russia) were added and the total volume was completed up to $20 \mu$ l by DEPC water. The mixture was then re-incubated in the thermal Cycler at $37^{\circ} \mathrm{C}$ for one hour, then at $90^{\circ} \mathrm{C}$ for $10 \mathrm{~min}$ to inactivate the enzyme.

\subsection{Semi-quantitative RT-PCR Analysis}

For semi-quantitative RT-PCR analysis, specific primers for examined genes (Table 1) were designed using Oligo-4 computer program and synthesized by Macrogen (Macrogen Company, GAsa-dong, Geumcheon-gu. Korea). PCR was conducted in a final volume of $25 \mu \mathrm{l}$ consisting of $1 \mu \mathrm{l}$ cDNA, $1 \mu \mathrm{l}$ of $10 \mathrm{pM}$ of each primer (forward and reverse), and $12.5 \mu \mathrm{l}$ PCR master mix (Promega Corporation, Madison, WI), the volume was brought up to $25 \mu \mathrm{l}$ using sterilized, deionized water. PCR was carried out using Bio-Rad $\mathrm{T} 100^{\mathrm{TM}}$ Thermal Cycle machine with the cycle sequence at $94^{\circ} \mathrm{C}$ for 5 minutes one cycle, followed by variable cycles (stated in Table 1) each of which consists of denaturation at $94^{\circ} \mathrm{C}$ for one minute, annealing at the specific temperature corresponding to each primer (Table 1) and extension at $72^{\circ} \mathrm{C}$ for one minute with additional final extension at $72^{\circ} \mathrm{C}$ for 7 minutes. As a reference, expression of glyceraldehyde-3phosphate dehydrogenase (G3PDH) mRNA was examined (Table 1). PCR products were electrophorized on $1.5 \%$ agarose gel stained with ethidium bromide in TBE (TrisBorate-EDTA) buffer. PCR products were visualized under UV light and photographed using gel documentation system. The intensities of the bands were quantified densitometrically using Image $\mathrm{J}$ software version 1.47 (http.//imagej.en.softonic.com/).

Table 1. PCR conditions of examined genes

\begin{tabular}{|c|c|c|c|}
\hline mRNA expression & Froward primer (5'-3') & Reverse primer (5’-3') & PCR cycles and Annealing \\
\hline PEPCK (236 bp) & TTTACTGGGAAGGCATCGAT & TCGTAGACAAGGGGGCAC & 30 cycles, $52^{\circ} \mathrm{C} 1 \mathrm{~min}$ \\
\hline GLUT-2 (230 bp) & AAGGATCAAAGCCATGTTGG & GGAGACCTTCTGCTCAGTGG & 30 cycles, $55^{\circ} \mathrm{C} 1 \mathrm{~min}$ \\
\hline ACO (633 bp) & GCCCTCAGCTATGGTATTAC & AGGAACTGCTCTCACAATGG & 35 cycles, $52^{\circ} \mathrm{C} 1 \mathrm{~min}$ \\
\hline GPT-1 (628 bp) & TATGTGAGGATGCTGCTTCC & CTCGGAGAGCTAAGCTTGCT & 35 cycles, $52^{\circ} \mathrm{C} 1 \mathrm{~min}$ \\
\hline ACS (484 bp) & GCCAAATGGCAAATTGAAG & TGCGCCATTTCCTCTAAGGA & 35 cycles, $52^{\circ} \mathrm{C} 1 \mathrm{~min}$ \\
\hline PPAR- $\alpha$ (680 bp) & GAGGTCCGATTCTTCCACTG & ATCCCTGCTCTCCTGTATGG & 35 cycles, $58^{\circ} \mathrm{C} 1 \mathrm{~min}$ \\
\hline FAS (345 bp) & CCAGAGCCCAGACAGAGAAG & GACGCCAGTGTTCGTTCC & 37 cycles, $61^{\circ} \mathrm{C} 45 \mathrm{sec}$ \\
\hline SREBP-1c (191bp) & GGAGCCATGGATTGCACATT & AGGAAGGCTTCCAAGAGAGGA & 35 cycles, $58^{\circ} \mathrm{C} 50$ sec \\
\hline Apo C III (305bp) & $\begin{array}{l}\text { ATGCAGCCCCAATGCTCCTCAT } \\
\text { CGTGGCC }\end{array}$ & $\begin{array}{c}\text { TCACGGCTCAAGAGTTGGTGTTGTTAGTT } \\
\text { GGTCCTCAGG }\end{array}$ & 35 cycles, $65^{\circ} \mathrm{C} 50 \mathrm{sec}$ \\
\hline GST (575 bp) & GCTGGAGTGGAGTTTGAAGAA & GTCCTGACCACGTCAACATAG & 35 cycles, $55^{\circ} \mathrm{C} 1 \mathrm{~min}$ \\
\hline Catalase (652 bp) & GCGAATGGAGAGGCAGTGTAC & GAGTGACGTTGTCTTCATTAGCACTG & 33 cycles, $55.5^{\circ} \mathrm{C} 1 \mathrm{~min}$ \\
\hline SOD (410 bp) & AGGATTAACTGAAGGCGAGCAT & TCTACAGTTAGCAGGCCAGCAG & 33 cycles, $55^{\circ} \mathrm{C} 1 \mathrm{~min}$ \\
\hline GAPDH (309 bp) & AGATCCACAACGGATACATT & TCCCTCAAGATTGTCAGCAA & 25 cycles, $52^{\circ} \mathrm{C} 1 \mathrm{~min}$ \\
\hline
\end{tabular}

\subsection{Liver Histopathology}

Rats were anesthetized with diethyl ether and the liver was incised. Livers were then removed from the rats and fixed overnight in a $10 \%$ buffered neutral formalin solution. Fixed tissues were processed routinely including washing, dehydration, clearing, paraffin embedding, casting, sectioning to $5 \mu \mathrm{m}$ sections for using in hematoxylin and eosin staining [31].

\subsection{Statistical Analysis}

Results were shown as means \pm standard error of means (SEM). Data were analyzed using analysis of variance (ANOVA) and post-hoc descriptive tests by SPSS software version 11.5 for Windows with $\mathrm{p}<0.05$ regarded as statistically significant. Regression analysis was performed using the same software. 


\section{Results}

\subsection{Effects of Mushroom, Chrysin, Curcumin and Omega-3 on Serum Biochemical Changes of Hypercholesterolemic Wistar Rats}

As shown in Table 2, induction of hypercholesterolemia in rats showed significant increase in serum levels of cholesterol, triglycerides, creatinine, urea, GPT and GOT. Compared to simvastatin (a well known hypolipidemic drug), there are a significant decrease in all parameters measured in hypercholesterolemic rats administered mushroom, chrysin, curcumin and omega-3. Triton induced hypercholesterolemic rats showed a decrease in HDL levels and normalized after administration of mushroom, chrysin, curcumin and omega-3 for 14 days.

Table 2. Antihypercholesterolemic effect of mushroom, chrysin, curcumin and omega-3 in Wistar rats with hypercholesterolemia

\begin{tabular}{|c|c|c|c|c|c|c|c|}
\hline & Cholesterol & TG & HDL & Creatinine & Urea & GPT & GOT \\
\hline Control & $77.7 \pm 6.4$ & $65 \pm 9.4$ & $20.5 \pm 0.6$ & $0.9 \pm 0.04$ & $43.7 \pm 5.2$ & $116.7 \pm 18.4$ & $90.5 \pm 3.4$ \\
\hline Triton & $506 \pm 79.3^{*}$ & $220 \pm 10 *$ & $9.1 \pm 0.4^{*}$ & $4.5 \pm 0.3^{*}$ & $123.73 \pm 13.2 *$ & $595.73 \pm 70.7 *$ & $422.5 \pm 59.43 *$ \\
\hline Simvistatin & $68.7 \pm 4.3 \#$ & $62 \pm 7.8 \#$ & $23 \pm 2 \#$ & $0.7 \pm 0.02 \#$ & $36.7 \pm 2.7 \#$ & $93.6 \pm 8.1 \#$ & $88.7 \pm 0.99 \#$ \\
\hline Mushroom & $76.2 \pm 4.7 \#$ & $69.3 \pm 8.5 \#$ & $22.7 \pm 1.6 \#$ & $0.7 \pm 0.1 \#$ & $33.5 \pm 3.1 \#$ & $115.2 \pm 8.4 \#$ & $120 \pm 27 \#$ \\
\hline Chrysin & $95.8 \pm 4 \#$ & $82 \pm 4.1 \#$ & $19.3 \pm 1.5 \#$ & $0.8 \pm 0.1 \#$ & $47.2 \pm 9.2 \#$ & $98.6 \pm 6.5 \#$ & $93 \pm 4.5$ \\
\hline Curcumin & $78.5 \pm 4.9 \#$ & $64.2 \pm 7.1 \#$ & $25 \pm 1.6 \#$ & $0.62 \pm 0.04 \#$ & $31.2 \pm 3.1 \#$ & $87.6 \pm 3.9 \#$ & $77.4 \pm 3 \#$ \\
\hline Omega 3 & $105.2 \pm 11.7 \#$ & $84.8 \pm 8.2 \#$ & $20.3 \pm 3.7 \#$ & $0.9 \pm 0.07 \#$ & $49 \pm 10.3 \#$ & $114 \pm 6.3 \#$ & $102.6 \pm 6.1 \#$ \\
\hline
\end{tabular}

Values are means \pm standard error (SE); $n=5$ for each treatment group; Values are statistically significant at * $<<0.05$ Vs. control and p\# < 0.05 Vs. Hypercholesterolemic Rats.

A

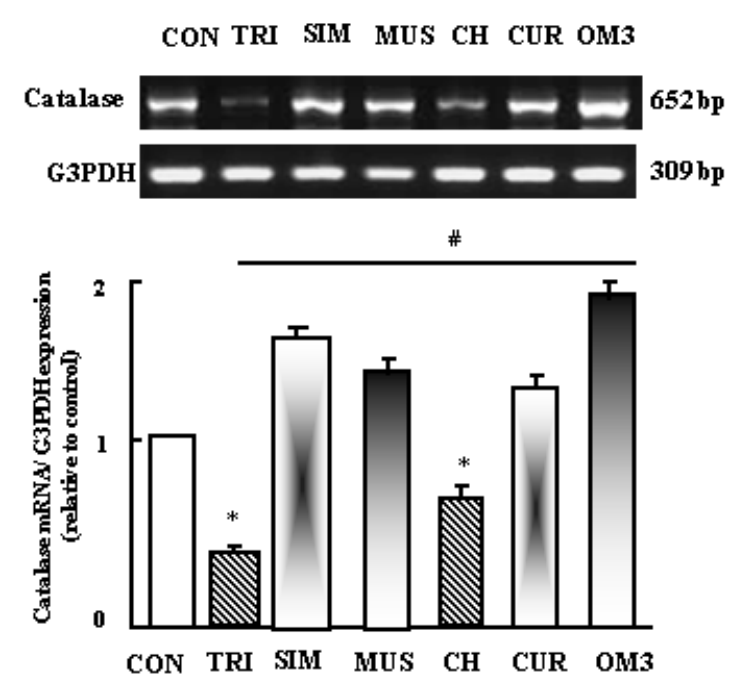

C
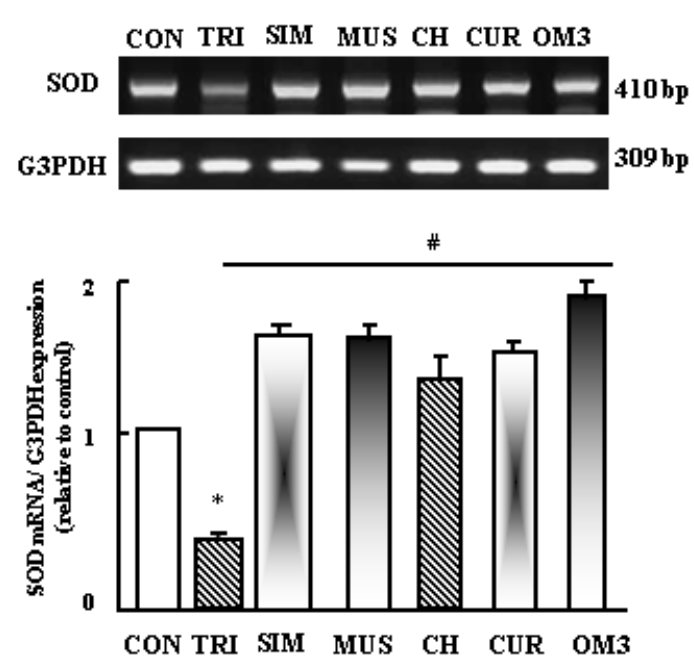

B

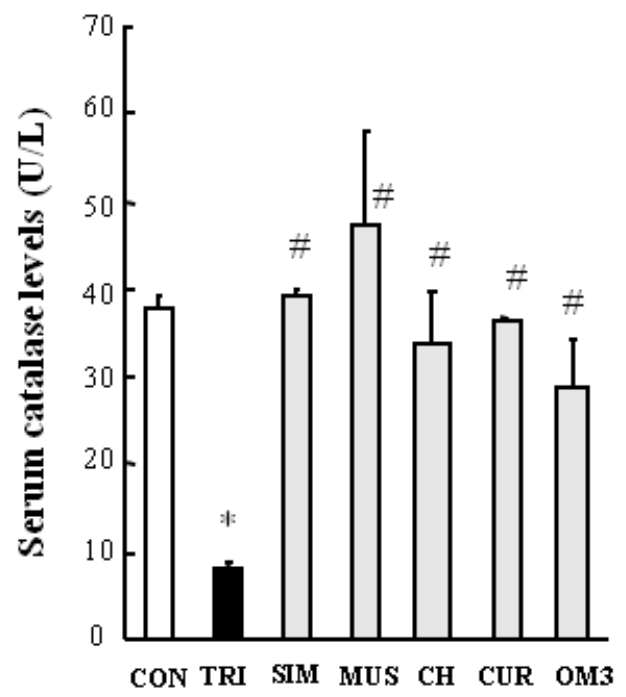

D

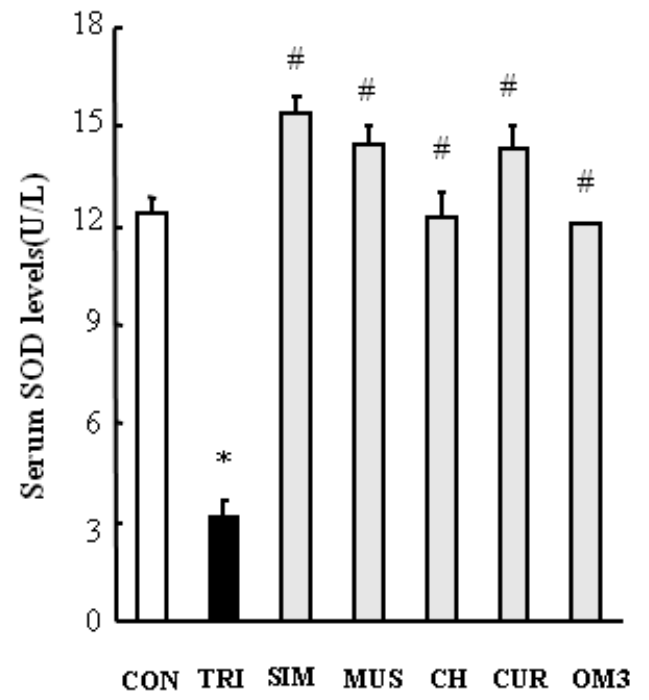

Figure 1. Protective effects of Mushroom, Chrysin, Curcumin and Omega-3 on mRNA expression of Catalase (A), SOD (C) and serum levels of catalase (B) and SOD (D) in Hypercholesterolemic Rats. RNA was extracted and reverse transcribed (1 $\mu$ g) and RT-PCR analysis was carried out for catalase, (A) and SOD (C) expression as described in materials and methods. Densitometric analysis was carried for 3 different experiments. Serum catalase and SOD levels were measured spectrophotometrically. Data are means \pm SEM for 3 independent experiments. Values are statistically significant at $* p<0.05$ Vs. control, $p \#<0.05$ Vs. Triton nd $\$ p<0.05 V$ s. control 
3.2. Effects of Mushroom, Chrysin, Curcumin and Omega-3 on Serum Levels and Gene Expression of Catalase and SOD in Hypercholesterolemic Wistar Rats

As shown in Figure 1, Triton decreased serum levels and mRNA expression of catalase and SOD. Administration

A

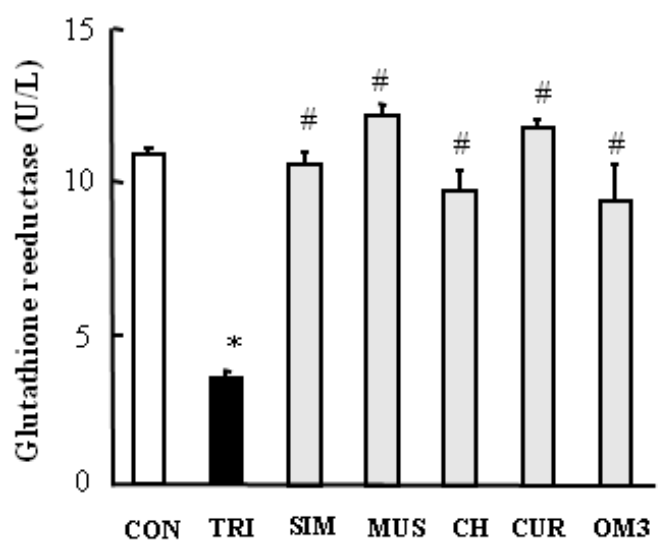

of mushroom, chrysin, curcumin and omega-3 showed beneficial effects, as they normalized and increased the serum levels and mRNA expression of catalase and SOD compared to Triton administered rats. There was a variation between administered treatments but without clear significant difference (Figure $1 \mathrm{~A}-\mathrm{D})$.

B

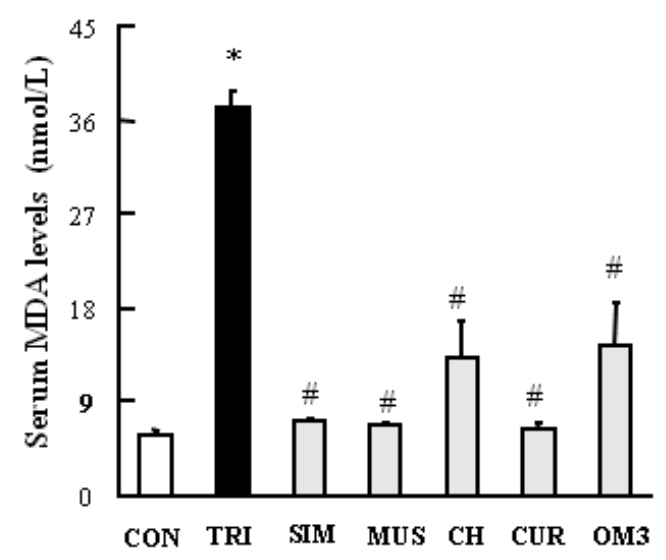

$\mathrm{C}$
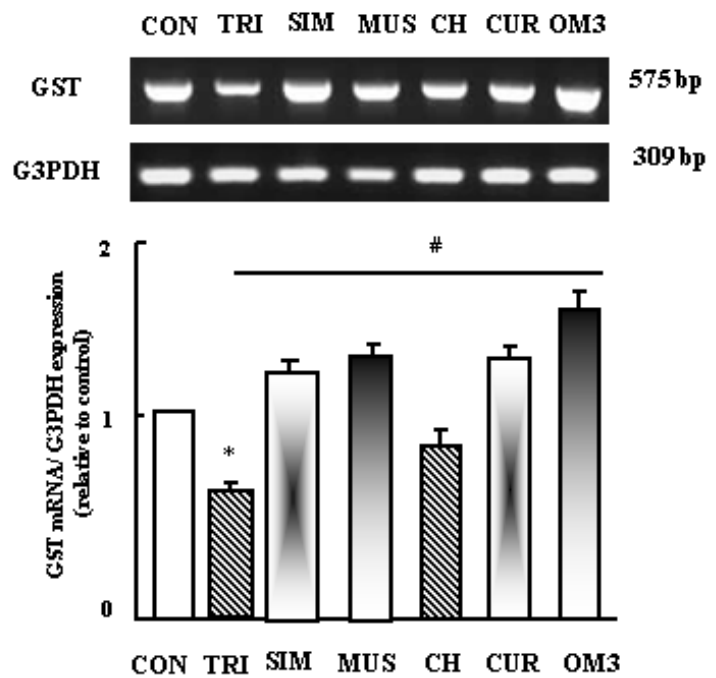

Figure 2. Protective effects of mushroom, chrysin, curcumin and omega-3 on Serum Levels of glutathione reductase (A), MDA (B) in blood and on hepatic mRNA expression GST in hypercholesterolemic rats. RNA was extracted and reverse transcribed $(1 \mu \mathrm{g})$ and RT-PCR analysis was carried out for GST (C) expression as described in materials and methods. Densitometric analysis was carried for 3 different experiments. Serum glutathione reductase and MDA levels were measured spectrophotometrically. Data are means \pm SEM for 3 independent experiments. Values are statistically significant at $* p<0.05$ Vs. control, $\# p<0.05$ Vs. Triton

\subsection{Effects of Mushroom, Chrysin, Curcumin and Omega-3 on Serum Levels of Glutathione Reductase, MDA and mRNA Expression of Glutathione-S-Transferase (GST) in Hypercholesterolemic Wistar Rats}

Hypercholesterolemia is associated with increase in oxidative stress and a decrease in antioxidants gene expression. As shown in Figure 2A, there was a significant decrease in serum levels of glutathione reducatse. Unlike glutathione reductase, Triton induced significant increase in serum levels of MDA confirming incidence of oxidative stress. The administration of mushroom, chrysin, curcumin and omega-3 normalized the decrease and increase in glutathione reducatse and
MDA respectively. GST expression in liver showed a decrease in Triton administered rats and a recovery by chrysin, mushroom, curcumin and omega-3 administrations (Figure $2 \mathrm{C}$ ).

\subsection{Effects of Mushroom, Chrysin, Curcumin and Omega-3 on the Expression of Genes Related to Fatty Acids Oxidation in Hypercholesterolemic Wistar Rats}

Dyslipidemia occurred after Triton administration is due to alteration in gene expression of fatty acids metabolism. Triton as shown in Figure 3 (A-D) induced significant decreases in the hepatic expressions of acyl CoA oxidase (ACO), and synthetase (ACS), carnitine 
palmitoyl transferase-1 (CPT-1) and peroxisome proliferator activator receptor- $\alpha$ (PPAR- $\alpha$ ). While, administration of mushroom, curcumin and omega-3 significantly normalized the reported decrease in the expression of examined genes. Chrysin showed partial significant normalization in the mRNA expression of examined genes (Figure 3 A-D).

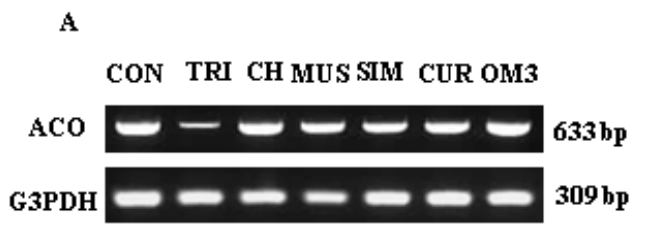

B

\#

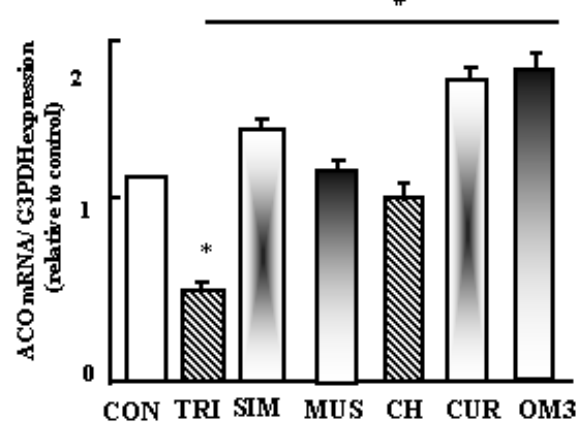
CON TRI SIM MUS CH CUR OM3
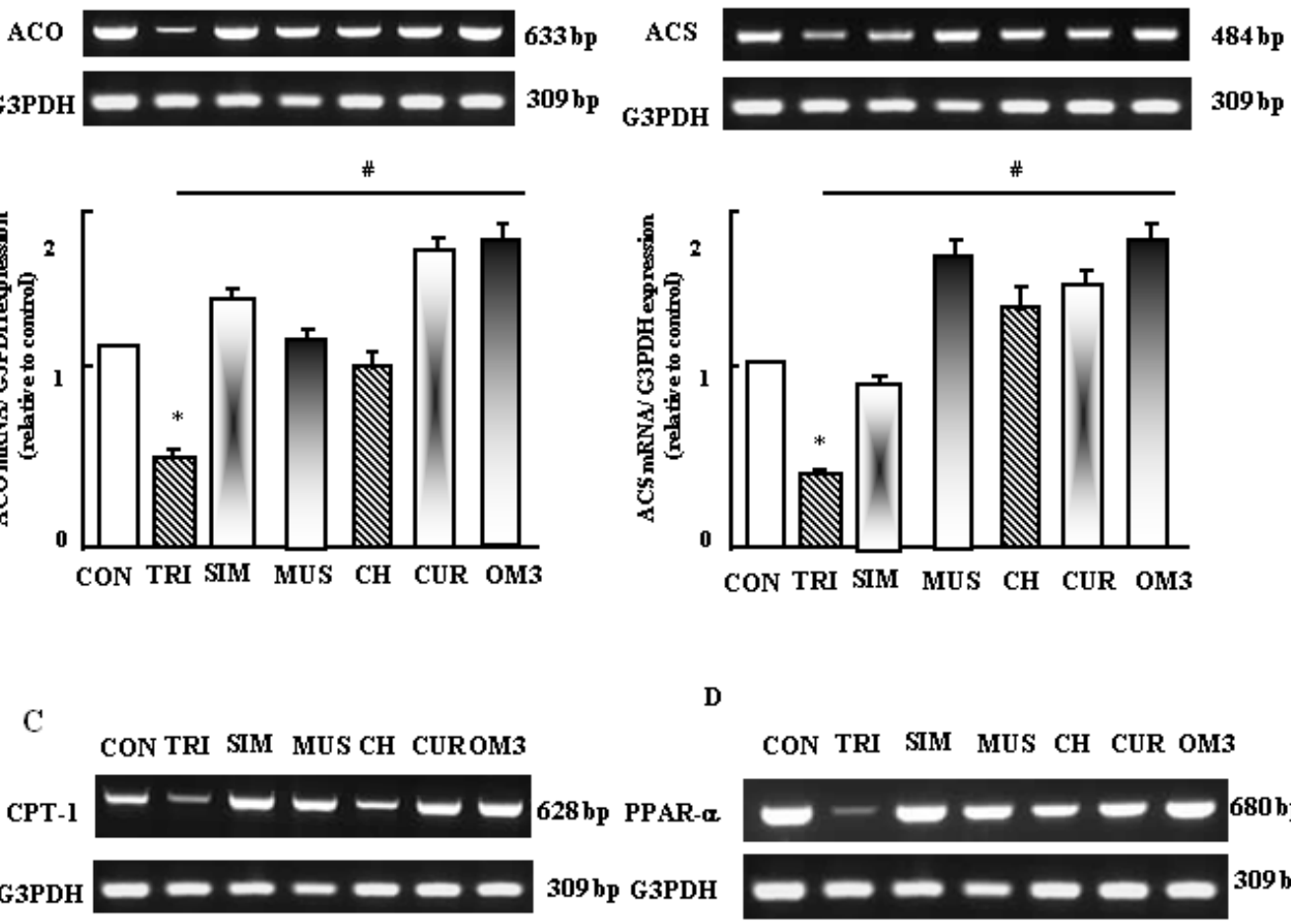

D CON TRI SIM MUS CH CUR OM3
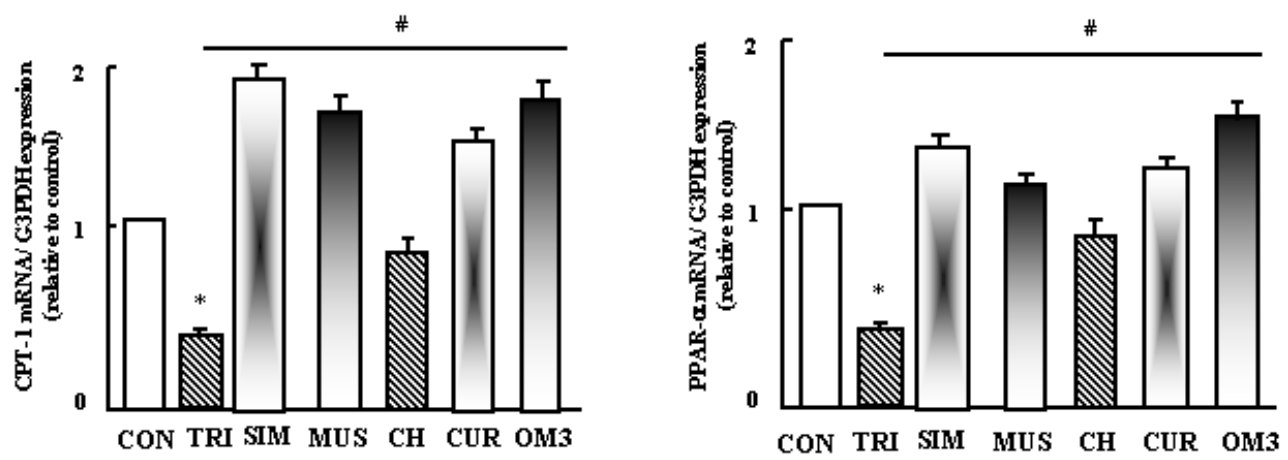

Figure 3. Protective effects of mushroom, chrysin, curcumin and omega- 3 on mRNA expression of ACO, ACS, CPT-1 and PPAR- $\alpha$ expression in liver tissue of Wistar rats using semi-quantitative RT-PCR analysis. RNA was extracted and reverse transcribed (1 $\mu \mathrm{g})$ and RT-PCR analysis was carried out for ACO (A), ACS (B), CPT-1 (C) and PPAR- $\alpha$ (D) expression as described in materials and methods. Densitometric analysis was carried for 3 different experiments. Data are means \pm SEM for 3 independent experiments. Values are statistically significant at $* p<0.05 V s$. control, $\# p<0.05$ Vs. Triton

\subsection{Effects of Mushroom, Chrysin, Curcumin and Omega-3 on the Expression of Genes Related to Fatty Acids Biosynthesis in Hypercholesterolemic Wistar Rats}

In contrast to the reported findings on the gene expression of fatty acids oxidation, there is an increase the expression of gene related to fatty acids biosynthesis and cholesterol metabolism. Triton as shown in Figure 4 (A-C) induced significant increases in the expression of fatty acids synthase (FAS), sterol responsible element binding protein -1c (STREBP-1c) and apolipoprotein CIII (apoCIII) expression in liver of Triton administered rats. Administration of mushroom, chrysin, curcumin and omega-3 significantly down-regulated the increase in the expression of examined genes (Figure 4 A-C).

\subsection{Effects of Mushroom, Chrysin, Curcumin and Omega-3 on the Expression of Genes Related to Glucose Metabolism in Hypercholesterolemic Wistar Rats}

In Triton hypercholesterolemic rats, PEPCK and glucose transporter-2 (GLUT-2) expression was decreased (Figure 5 A-B). Administration of mushroom, chrysin, curcumin and omega-3 returned PEPCK expression to normal levels of control rats (Figure 5A). Unlike PEPCK, the expression of GLUT-2 is individually affected by treatments. Figure 5B, showed that only mushroom and curcumin significantly normalized the down regulation of GLUT-2 expression. Chrysin and omega-3 failed to completely normalize the expression of GLUT-2 expression compared to control, Triton and simvastatin administered rats. 
A

CON TRI SIM MUS CH CUR OM3

FAS

G3PDH

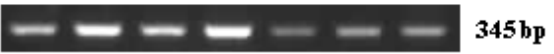

$-\infty-\infty \omega 309$ bp

B

CON TRI SIM MUS CH CUR OM3

SREBP-1c

G3PDH

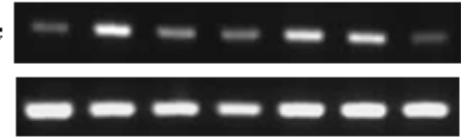

$190 \mathrm{bp}$

309 bp

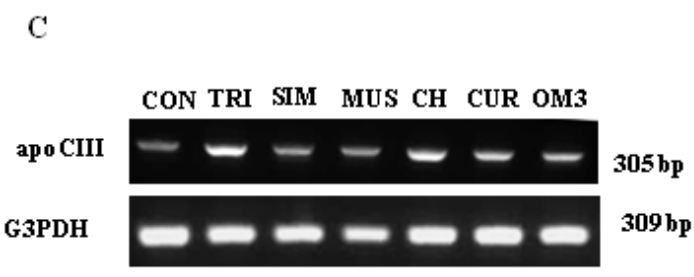

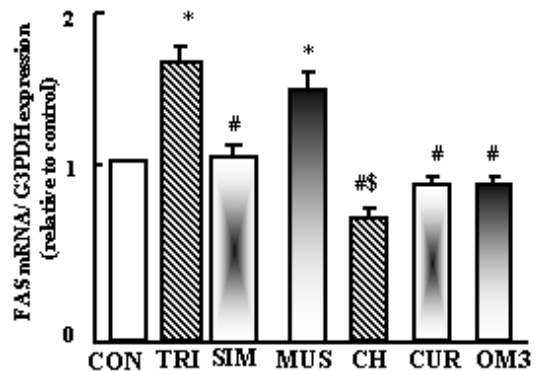

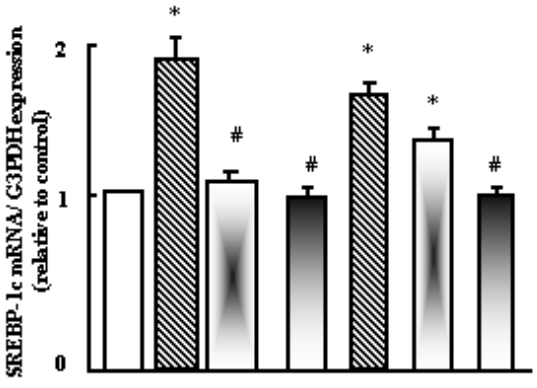

CON TRI SIM MUS CH CUR OM3

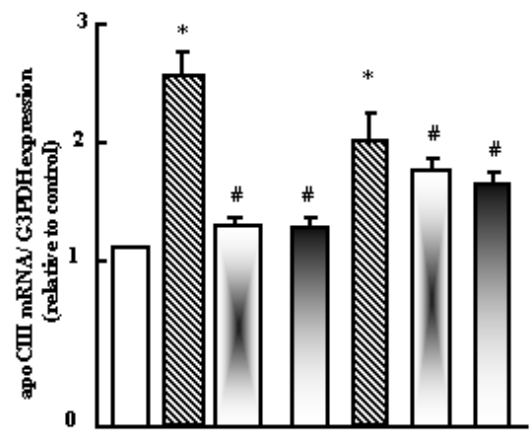

CON TRI SIM MUS CH CUR OM

Figure 4. Protective effects of mushroom, chrysin, curcumin and omega-3 on mRNA expression of FAS, STREBP-1c and apoCIII expression in liver tissue of Wistar rats using semi-quantitative RT-PCR analysis. RNA was extracted and reverse transcribed $(1 \mu \mathrm{g})$ and RT-PCR analysis was carried out for FAS (A), STREBP-1c (B) and apoCIII (C) expression as described in materials and methods. Densitometric analysis was carried for 3 different experiments. Data are means \pm SEM for 3 independent experiments. Values are statistically significant at ${ }^{*} p<0.05 V s$. control, \#p $<0.05$ Vs. Triton

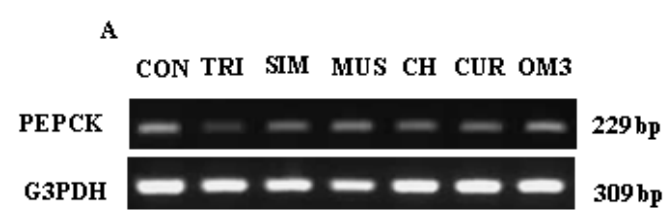

B

CON TRI SIM MUS CH CUR OM3
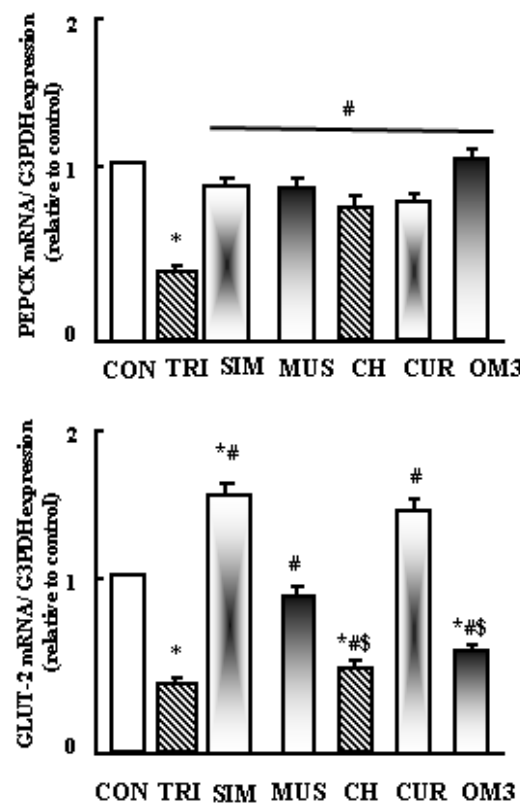

Figure 5. Protective effects of mushroom, chrysin, curcumin and omega-3 on mRNA expression of FPEPCK, and GLUT-2 expression in liver tissue of Wistar rats using semi-quantitative RT-PCR analysis. RNA was extracted and reverse transcribed $(1 \mu \mathrm{g})$ and RT-PCR analysis was carried out for FPEPCK (A), and GLUT-2 (B) expression as described in materials and methods. Densitometric analysis was carried for 3 different experiments. Data are means \pm SEM for 3 independent experiments. Values are statistically significant at ${ }^{*} p<0.05 V s$. control, \#p $<0.05$ Vs. Triton and $\$ p<0.05$ Vs. simvastin 


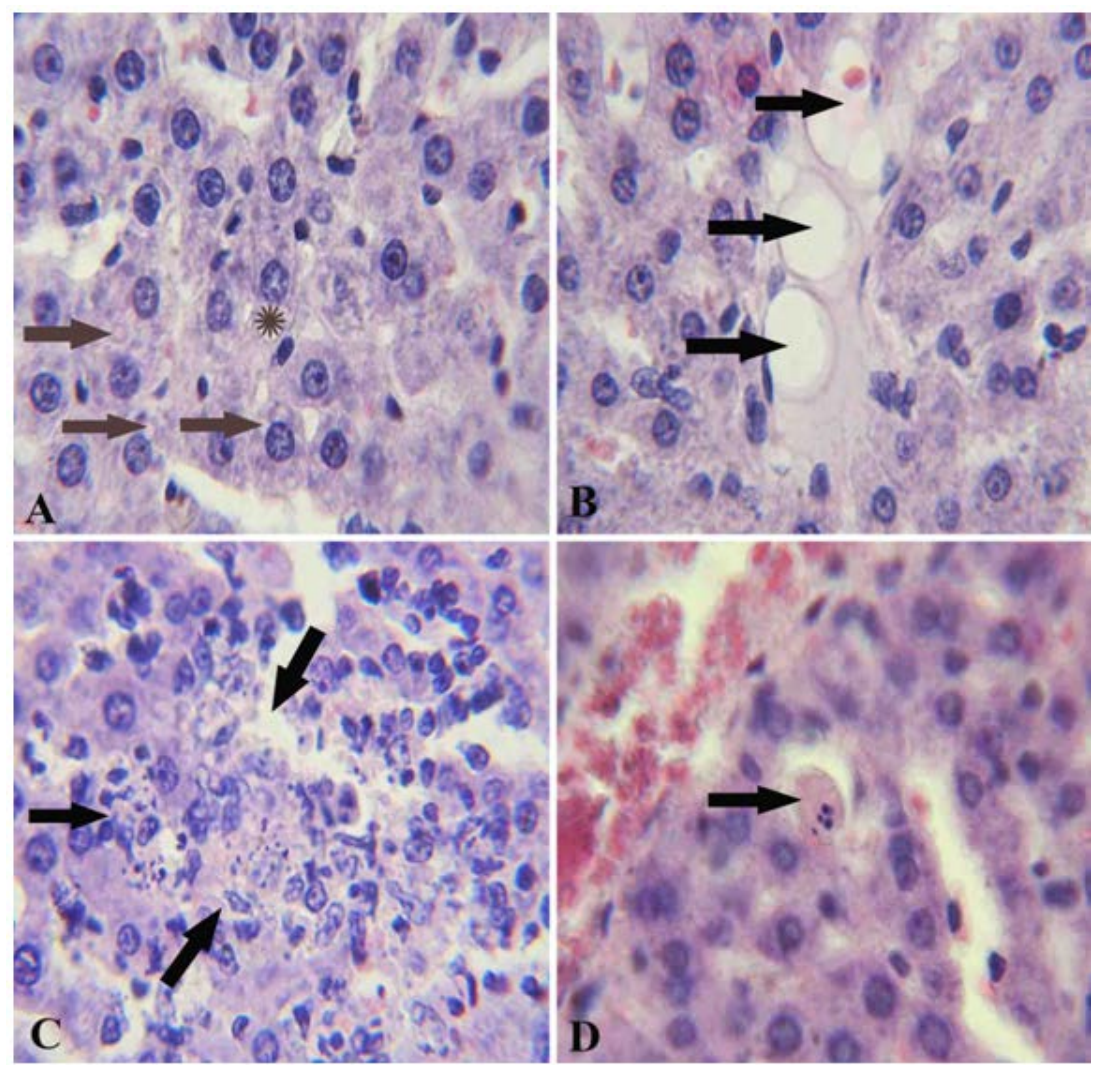

Figure 6. liver of triton group. A, liver of triton group showed accumulation of large $\left(^{*}\right)$ and tiny (arrows) fat droplets inside the hepatocytes. B, Deposition of large fat droplets could also be detected among hepatocytes (arrows). C, Liver also showed focal areas for degeneration and necrosis with fragmentation of nuclear chromatin and infiltration of some leukocytes in the necrotic arease (arrows). D, Presence of apoptotic hepatocytes could also be observed (arrow). H\&E × 1200
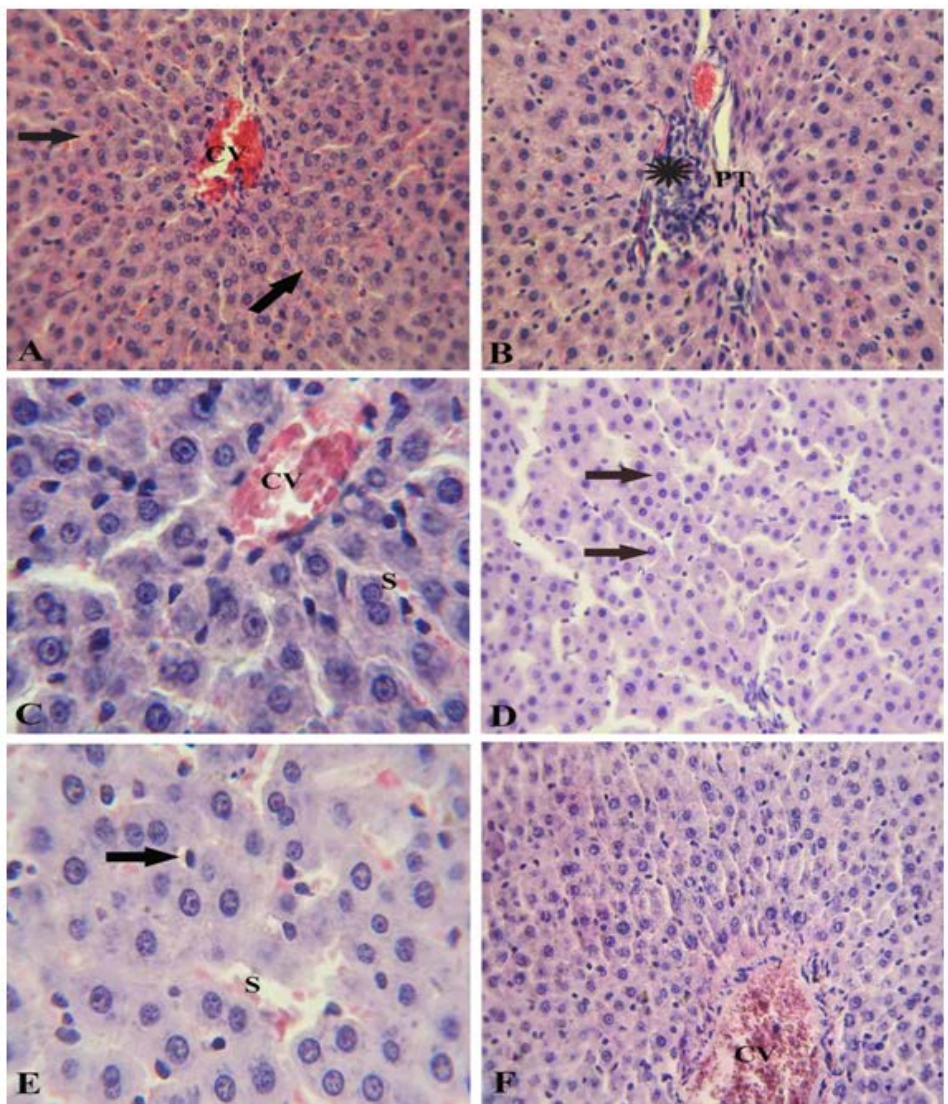

Figure 7. A, liver of control group showed normal hepatic architecture with presence of a central vein (CV) surrounded by normal radiating hepatic cords with hepatic sinusoids in-between (arrows). H\&E $\times 300$. B, Liver of simvastatin group showed normal hepatocytes and sinusoids, portal tract (PT) appears normal with presence of mild leukocytic infiltration $(*)$. H\&E $\times 300$. C, Liver of curcumin group showed central vein (CV), normal hepatocytes and sinusoids (S). H\&E $\times 1200$. D, Liver of omega-3 group showing normal hepatocytes and sinusoids with absence of fat droplets (arrows). H\&E× 300 . E, Liver of chrysin group showed normal hepatic cells with presence of few lipid laden Kupffer cells (arrow). H\&E $\times 1200$. F, Liver of mushroom group showing congestion of central vein (CV) surrounded by radiating hepatocyte plates. H\&E× 300 


\subsection{Effects of Mushroom, Chrysin, Curcumin and Omega-3 on Liver Histopathology in Hypercholesterolemic Wistar Rats}

Liver of Triton group showed accumulation of large and tiny fat droplets inside the hepatocytes (Figure 6A). Deposition of large fat droplets could also be detected among hepatocytes (Figure 6B). Liver also showed focal areas of degeneration and necrosis with fragmentation of nuclear chromatin and infiltration of some leukocytes in the necrotic areas (Figure 6C). Presence of apoptotic hepatocytes could also be observed (Figure 6D). While the control group showed normal hepatic architecture with presence of a central vein surrounded by normal radiating hepatic cords with hepatic sinusoids in-between (Figure 7A). Liver of simvastatin group showed normal hepatocytes and sinusoids, portal tract appears normal with presence of mild leukocytic infiltration (Figure 7B). Liver of curcumin group showed normal hepatocytes and sinusoids (Figure 7C). Liver of omega-3 group showed normal hepatocytes and sinusoids with absence of fat droplets (Figure 7D). Liver of chrysin group showed normal hepatic cells with presence of few lipid laden Kupffer cells (Figure 7E). Liver of mushroom group showed congestion of central vein surrounded by radiating hepatocyte plates with normal portal tracts surround the classical lobules (Figure 7F).

\section{Discussion}

The current study showed that the usage of alternative herbal medications such as mushroom, chrysin, curcumin and omega-3 have antihypercholesterolemic effects in Triton WR1339 induced hypercholesterolemia. Triton WR1339 (Tyloxapol) is widely used to induce hypercholesterolemia in animal models [32]. It inhibits the activity of lipoprotein lipase, resulting in the accumulation of triglycerides (TG) and VLDL in plasma, beyond causes a significant increase in hepatic cholesterol biosynthesis by stimulating the activity hydroxy-3-methylglutaryl- CoA (HMG-CoA) reductase [32]. Moreover, Triton increases the production of free radicals by enhancing mitochondrial respiration and down regulating the antioxidant system [33]. Alterations in serum levels of hepatic transaminases indicate liver damage and necrosis [27,34]. Like ours, many studies reported malfunctioning of the liver transaminases due to the intracellular accumulation of lipids and microvesicular steatosis [35]. In hyperlipidemia, increased hepatic transaminases escape to the plasma from the injured hepatic cells [36]. Therefore, the increment of the activities of hepatic transaminases in plasma may be mainly due to leakage of these enzymes from the liver cytosol into blood stream [37]. This leakage causes a decrease in levels of GOT and GPT in hepatic cells but increase their levels in serum [38].

In the current study simvastatin was used as a wellknown lipid-lowering drug by competitively inhibiting HMG-CoA reductase activity, which plays a major role in cholesterol biosynthesis [39,40]. The results of simvastatin on serum TG levels could be explained through elevation of lipoprotein lipase activity by increasing lipase mRNA expression [41] and through suppression of diacyl glycerol acyl transferase, which catalyzes the final step in TG biosynthesis in the rat liver microsomes [26,27,42]. Here, administration of mushroom extract, chrysin, curcumin and omega-3 as well as simvastatin to hypercholesterolemic rats resulted in reduction of serum levels of total cholesterol and TG, and elevation of HDLcholesterol than those in hypercholesterolemic rats.

During hypercholesterolemic, atherogenesis and oxygen-free radicals are generated [43]. Living tissues are endowed with innate antioxidant defense mechanisms, including CAT, SOD, and glutathione peroxidase (GPx), that are involved in the disposal of superoxide anions and $\mathrm{H}_{2} \mathrm{O}_{2}$ [44]. A reduction in the activity of antioxidants is associated with the accumulation of highly reactive free radicals that cause deleterious effects, such as loss of integrity and function of cell membranes [44]. In the present study, Triton WR-1339 administration increased the oxidative stress biomarker MDA, and decreased the activity and mRNA expression of antioxidant enzymes (catalase, SOD, glutathione reductase and GST). It has been shown that 18 hours after Triton WR-1339 administration, the level of plasma ROS were increased and the activity of catalase and GPx were decreased compared to control group $[28,45]$. In this study, those alterations were normalized by administration of mushroom, chrysin, curcumin and omega-3 as did simvastatin. Similar results were reported by Anandhi et al who explained that mushroom extract and chrysin possibly acted by neutralizing the free radicals generated during hypercholesterolemia [27]. The observed increase in MDA in hypercholesterolemic rats is possibly resulted from increased intensity of lipid peroxidation [46,47]. Chrysin significantly increased GSH, CAT, GSH and $\mathrm{Cu} / \mathrm{Zn}$ SOD levels [48] and has the capability of free radicals scavenging [49]. Curcumin normalized the decrease in antioxidant enzyme expression that is observed in hypercholesterolemic rats. Palipoch et al and Naik et al confirmed the protective effect of curcumin in normalizing the levels of liver enzymes and lipid peroxidation biomarkers [50,51]. Omega-3 has also the potential protective role against ROS-induced oxidative cellular damage in rat organs, especially in the liver [52]. These results are of great importance since flavonoids are viewed as important components of 'functional foods', acting as modifiers of cardiovascular disease [53]. Therefore, it is desirable to develop natural drugs that have cholesterol-lowering action without side effects.

Lipid-lowering effects of mushroom and chrysin were due to inhibition of cholesterol biosynthesis and/or increase in fecal bile acid excretion [54]. Moreover, chrysin causes an increase in triglycerides catabolism and stimulates plasma lipoprotein lipase activity [28]. Mushroom administration reduces cholesterol levels and has great significance in prevention of hyperlipidemia or cardiovascular disease $[14,27,28]$. HDL-cholesterol is good for health, since it facilitates mobilization of triglycerides and cholesterol from the plasma to the liver [55]. Curcumin decreases the expression of FAS, a key enzyme in the de novo long-chain FA synthesis pathway [56]. Moreover, curcumin enhanced FA $\beta$-oxidation in adipocytes with a concomitant increase in the expression of CPT-1, a key enzyme in transferring acyl-CoA into mitochondria for $\beta$-oxidation [57]. Curcumin reduced mRNA levels of SREBP1-c, a key transcription factor for hepatic lipogenesis [58]. Dietary polyphenols like curcumin prevented obesity development through a decrease in food intake and lipogenesis, increase in lipolysis, stimulate FA $\beta$-oxidation, and suppress oxidative stress 
[59]. Therefore, curcumin inhibited hypercholesterolemia by regulating the mRNA expression of genes related to fatty acids biosynthesis and oxidation.

Omega-3 treated animals showed the best hypolipidemic effect compared to other groups. Omega-3 is lipidlowering drug in animal models and human studies [60]. It has been shown that omega- 3 convey its beneficial effects via the activation of the nuclear receptor PPAR- $\alpha$ to enhance fat catabolism [61]. PPAR- $\alpha$ is predominantly expressed in the liver and regulates the transcription of genes involved in hepatic lipid uptake and oxidation, including ACO, ACS, CPT-1 and lipoprotein lipase (LPL) [62]. The lipid-lowering effect of omega-3 in liver is not solely due to acceleration of fatty acid oxidation by PPAR- $\alpha$ activation but due to its effect on other signaling pathways. Moreover, omega-3 regulated the expression of SREBP-1c and FAS (Figure 4A-B) as supported by other studies $[63,64]$. The decrease in apoCIII expression is due to the upregulation in PPAR- $\alpha$ expression, thus contributing to the lipid and lipoprotein lowering properties of fish or fish oil intake [65].

Accumulation of fat droplets during hyperlipidemia reported inside the hepatocytes with degeneration, necrosis and apoptosis is the result of a) blocking the uptake of triacylglycerol-rich lipoproteins from plasma by peripheral tissues, b) stimulating the hepatic cholesterol biosynthesis [66]. Recovery of lipid accumulation was detected in mushroom, chrysin, curcumin and omega-3 groups as did simvastatin. The regeneration of histological changes occurred in hypercholesterolemic group are attributed to antioxidant effect of curcumin, mushroom and omega-3 FA and this is also in accordance with other studies [67,68]. Pretreatment with curcumin and $\alpha$ tocopherol improved liver enzymes levels and lipid peroxidation biomarker, the activities of enzymatic antioxidants, liver histopathology and gene expression of hepatic NADPH oxidase in cisplatin-treated rats [50]. In conclusion, this study clarified the beneficial effects of herbal plants and omega-3 in ameliorating the biohazards induced by hypercholesterolemia in Wistar rats at both molecular and cellular levels.

\section{Funding and Acknowledgements}

The authors would like to acknowledge and thank the Deans of Scientific Research Affairs in Taif University, Saudi Arabia for financial support of this study (project number 3103-35-1).

\section{References}

[1] Formiguera X, Canton A. "Obesity: epidemiology and clinical aspects”, Best Pract Res Clin Gastroenterol., 18. 1125-1146. 2004.

[2] Dhaliya, S.A., Surya, A.S., Dawn, V.T., Betty, C., Arun, K. and Sunil, C. "A review of hyperlipidemia and medicinal plants", Int.J.A.PS. BMS., 2(4). 219-237. 2013.

[3] Freedman, J. E. "High-fat diets and cardiovascular disease. Are nutritional supplements useful?”, Journal of the American College of Cardiology., 41 (10).1750-1752. 2003.

[4] Duarte MM, Rocha JB, Moresco RN, Duarte T, Da Cruz IB, Loro VL, Schetinger MR. "Association between ischemia-modified albumin, lipids and inflammation biomarkers in patients with hypercholesterolemia”, Clinical Biochemistry, 42 (7-8). 666-671. 2009.

[5] Hopps, E., Noto, D., Caimi, G. and Averna, M.R. "A novel component of the metabolic syndrome: the oxidative stress", Nutr Metab Cardiovasc Dis., 20. 72-77. 2010.
[6] Hamelet, J., Demluth, K., Paul, J.L., Delabar, J.M. and Janel, N. "Hyperhomo-cysteinemia due to cystathionine beta synthase deficiency induces dysregulation of genes involved in hepatic lipid homeostasis in mice”, J Hepatol., 46(1). 151-159. 2007.

[7] Kumar, S.A., Sudhahar, V. and Varalakshmi, P. "Protective role of eicosapentaenoate-lipoate (EPA-LA) derivative in combating oxidative hepatocellular injury in hypercholesterolemic atherogenesis”, Atherosclerosis, 189(1). 115-122. 2006.

[8] Eghdamian, B. and Ghose, K. "Mode of action and adverse effects of lipid lowering drugs”, Drugs Today (Barc), 34. 943-956. 1998.

[9] Kumar, A.S., Mazumder, A. and Saravanan, V.S. "Antihyperlipidemic activity of Camellia sinensis leaves in triton wr-1339 induced Albino rats”, Pharmacogn Mag., 4.60-64. 2008.

[10] Khanna, P. and Garcha, H.S. "Pleurotus mushroom - a source of food protein”, Mushrooms News letter Tropical, 4.9-14. 1984.

[11] Jayakumar, T., Thomas, P.A., and Geraldine, P. "In-vitro antioxidant activities of an ethanolic extract of the oyster mushroom, Pleurotus ostreatus”, Inn Food Sci Emerg Tech., 10.228-234. 2009.

[12] Bae, J., Sinha, J., Park, J.P., Song, C.H. and Yun, J.W. "Optimization of submerged culture conditions for exobiopolymer production by Paecilomyces Japanica”, J Microbiol Biotechnol., 10(4). 482-487. 2000.

[13] Kanagasabapathy, G., Malek, S.N.A., Mahmood, A.A., Chua, K.H., Vikineswary, S. and Kuppusamy, U.R. "Beta-Glucan-Rich Extract from Pleurotus sajor-caju (Fr.) Singer Prevents Obesity and Oxidative Stress in C57BL/6J Mice Fed on a High-Fat Diet”, Evidence-Based Complementary and Alternative Medicine, 1-10. 2013.

[14] Jegadeesh, R., Raaman, N., Hariprasath, L., Ramesh, V. and Srikumar, R. "Hypolipidemic Effect of Pleurotus djamor var. roseus in Experimentally Induced Hypercholesteromic Rats", Research Journal of Pharmaceutical, Biological and Chemical Sciences, 5(2). 581-588. 2014.

[15] Phan, T., Yu, X.M., Kunnimalaiyaan, M. and Chen, H. "Antiproliferative effect of chrysin on anaplastic thyroid cancer", J Surg Res., 170(1). 84-88. 2011.

[16] Pushpavalli, G., Veeramani, C. and Pugalendi, K.V. "Influence of chrysin on hepatic marker enzymes and lipid profile against dgalactosamine-induced hepatotoxicity rats", Food Chem Toxicol., 48(6). 1654-1659. 2010.

[17] Sobocanec, S., Sverko, V., Balog, T., Saric, A., Rusak, G., Likic, S., Kusic, B., Katalinic, V., Radic, S. and Marotti, T. "Oxidant/antioxidant properties of Croatian native propolis", $J$ Agric Food Chem., 54(21). 8018-8026. 2006.

[18] Aggarwal, B.B. "Targeting inflammation-induced obesity and metabolic diseases by curcumin and other nutraceuticals”, Annu Rev Nutr., 30. 173-199. 2010.

[19] Meydani, M. and Hasan, S.T. "Dietary polyphenols and obesity. Nutrients, 2. 737. 2010.

[20] Gao, S., Duan, X., Wang, X., Dong, D., Liu, D., Li, X., Sun, G. and $\mathrm{Li}, \mathrm{B}$. "Curcumin attenuates arsenic-induced hepatic injuries and oxidative stress in experimental mice through activation of Nrf2 pathway, promotion of arsenic methylation and urinary excretion”, Food Chem Toxicol., 59. 739-747. 2013.

[21] Bradford, P.G. "Curcumin and Obesity", International Union of Biochemistry and Molecular Biology Inc., 39(1). 78-87. 2013.

[22] Bosch, J., Gerstein, H.C., Dagenais, G.R., Diaz, R., Dyal, L., Jung, H., Maggiono, A.P., Probstfield, J., Ramachandran, A., Riddle, M.C., Rydén, L.E. and Yusuf, S. "N-3 fatty acids and cardiovascular outcomes in patients with dysglycemia”, $N$ Engl $J$ Med., 367. 309-318. 2012.

[23] Mozaffarian, D., Lemaitre, R.N., King, I.B., Song, X., Huang, H., Sacks, F.M., Rimm E.B., Wang, M. and Siscovick, D.S. "Plasma phospholipid long-chain omega-3 fatty acids and total and causespecific mortality in older adults: a cohort study”, Ann Intern Med., 158. 515-525. 2013.

[24] Lorente-Cebrián, S., Costa, A.G.V., Navas-Carretero, S., Zabala, M., Martínez, J.A and Moreno-Aliaga, M.J. "Role of omega-3 fatty acids in obesity, metabolic syndrome, and cardiovascular diseases: a review of the evidence”, J Physiol Biochem., 69.633651. 2013.

[25] Rossmeisl, M., Medrikova, D., van Schothorst, E.M., Pavlisova, J., Kuda, O., Hensler, M., Bardova, K., Flachs, P., Stankova, B., Vecka, M., Tvrzicka, E., Zak, A., Keijer, J. and Kopecky, J. "Omega-3 phospholipids from fish suppress hepatic steatosis by integrated inhibition of biosynthetic pathways in dietary obese 
mice”, Biochim Biophys Acta - Mol Cell Biol. Lipid, 1841. 267278. 2014.

[26] Venkadeswaran, K., Muralidharan, A.R., Annadurai, T., Ruban, V.V., Sundararajan, M., Anandhi, R., Thomas, P.A. and Geraldine, P. "Antihypercholesterolemic and Antioxidative Potential of an Extract of the Plant, Piper betle, and Its Active Constituent, Eugenol, in Triton WR-1339-Induced Hypercholesterolemia in Experimental Rats”, Evid Based Complement Alternat Med., 1-11. 2014.

[27] Anandhi, R., Annadurai, T., Anitha, T.S., Muralidharan, A.R., Najmunnisha, K., Nachiappan, V., Thomas, P.A. and Geraldine, P. "Antihypercholesterolemic and antioxidative effects of an extract of the oyster mushroom, Pleurotus ostreatus, and its major constituent, chrysin, in Triton WR-1339-induced hypercholesterolemic rats”, J Physiol Biochem., 69(2).313-23. 2013.

[28] Zarzecki, M.S., Araujo, S.M., Bortolotto, V.C., De Paula. M.T., Jesse, C.R. and Prigol, M. "Hypolipidemic action of chrysin on Triton WR-1339-inducedhyperlipidemia in female C57BL/6 mice”, Toxicology Reports, 1. 200-208. 2014.

[29] Öner-İyidoğan Y, Koçak H, Seyidhanoğlu M, Gürdöl F, Gülçubuk A, Yildirim F, Çevik A, Uysal M. "Curcumin prevents liver fat accumulation and serum fetuin-A increase in rats fed a high-fat diet”, J Physiol Biochem. 2013, 69(4).677-86.

[30] Flachs, P., Rossmeisl, M., Bryhn, M. and Kopecky. "Cellular and molecular effects of $\mathrm{n}-3$ polyunsaturated fatty acids on adipose tissue biology and metabolism”, Clinical Science., 116. 1-16. 2009.

[31] Bancroft, J.D. and Gamble, M. "Theory and Practice of Histological Techniques”, 6th ed. Churchill Livingstone Elsevier Philadelphia, 126-127. 2008.

[32] Bertges, L.C., Souza Mourão, CAJr, J.B. and Cardoso, V.A.C. "Hyperlipidemiainduced by Triton WR1339 (Tyloxapol) in Wistar rats”, Rev. Bras. Cien.Med. Saúde., 1(1). 32-34. 2011.

[33] Vijayaraj, P., Muthukumar, K., Sabarirajan, J. and Nachiappan, V. "Antihyperlipidemic activity of Cassia auriculata flowers in triton WR 1339 induced hyperlipidemic rats”, Exp Toxicol Pathol. 2011.

[34] Thapa, B.R. and Walia, A. "Liver function tests and their interpretation”, Indian J Pediatr., 74. 663-671. 2007.

[35] Dixon, J.B., Bhathal, P.S. O and Brien, P.E. "Nonalcoholic Fatty Liver Disease. Predictors of Nonalcoholic Steatohepatitis and Liver Fibrosis in the Severely Obese", Gastroenterology, 121(1). 91-100. 2001.

[36] Hassoun, E.A. and Stohs, S.J. "Comparative studies on oxidative stress as a mechanism for the fetotoxic of TCDD, endrin and lindane in C57BL/6J and DBA/2J mice", Teratology, 51. 186. 1995.

[37] El-Demerdash, F.M., Yousef, M.I. and Zoheir, M.A. "Stannous chloride induces alterations in enzyme activities, lipid peroxidation and histopathology in male rabbit: antioxidant role of vitamin C”, Food Chem Toxicol., 43(12). 1743-52. 2005.

[38] Yadav, N.P. and Dixit, V.K. "Hepatoprotective activity of leaves of Kalanchoe pinnata Pers”, J Ethanopharmacol., 86, 197-202. 2003.

[39] Kausar, S., Zaheer, Z., Saqib, M. and Zia, B. "The effect of Crataegus (Hawthorn) extract alone and in combination with simvastatin on serum lipid profile in hyperlipidemic albino rats”, Biomedica., 27. 140-147. 2011.

[40] Wu, Y., Li, J., Wang, J., Si, Q., Zhang, J., Jiang, Y. and Chu, L. "Anti-atherogenic effects of centipede acidic protein in rats fed an atherogenic diet”, J Ethnopharmacol., 122(3). 509-516. 2009.

[41] Benhizia, F., Lagrange, D., Malewiak, M.I.N. and Griglio, S. "In vivo regulation of hepatic lipase activity and mRNA levels by diets which modify cholesterol influx to the liver", Biochim. Biophys. Acta Lipids lipid Metabol., 1211(2). 181-188. 1994.

[42] Waterman, I.J. and Zammit, V.A. "Differential effects of fenofibrate or simvastatin treatment of rats on hepatic microsomal overt and latent diacylglycerol acyltransferase activities”, Diabetes, 51(6). 1708-1713. 2002.

[43] Prasad, K. and Kalra, J. "Oxygen free radicals and hypercholesterolemic atherosclerosis: effect of vitamin E", Am Heart J., 125.958-973. 1993.

[44] Halliwell, B. "Lipid peroxidation, antioxidants and cardiovascular disease: how should we move forward?”, Cardiovasc Res., 47.410-418. 2000.

[45] Oh, P.S., Lee, S.J. and Lim, K.T. "Hypolipidemic and antioxidative effects of the plant glycoprotein $(36 \mathrm{kDa})$ from Rhus verniciflua stokes fruitin Triton WR-1339-induced hyperlipidemic mice”, Biosci Biotechnol Biochem., 70(2). 447-456. 2006.
[46] Wissler, R.W. "Theories and new horizons in the pathogenesis of atherosclerosis and the mechanisms of clinical effects", Arch Pathol Lab Med., 116.1281-1291. 1992.

[47] Williams, C.A., Harborne, J.B., Newman, M., Greenham, J. and Eagles, J. "Chrysin and other leaf exudate flavonoids in the genus Pelargonium”, Phytochemistry, 46.1349-1353. 1997.

[48] Ciftci, O., Ozdemir, I., Aydin, M. and Beytur, A. "Beneficial effects of chrysin on the reproductive system of adult male rats", Andrologia, 44 (3). 181-186. 2012.

[49] Rice-Evans, C.A. "Flavonoid antioxidants", Curr Med Chem., 8 (7).797-807. 2001.

[50] Palipoch, S., Punsawad, C., Koomhin, P. and Suwannalert, P. "Hepatoprotective effect of curcumin and alpha-tocopherol against cisplatin-induced oxidative stress", BMC Complementary and Alternative Medicine, 14.111. 2014.

[51] Naik, S.R., Thakare, V.N. and Patil, S.R. "Protective effect of curcumin on experimentally induced inflammation, hepatotoxicity and cardiotoxicity in rats. Evidence of its antioxidant property", Exp Toxicol Pathol., 63(5).419-431. 2011.

[52] Di Minno, M.N., Russolillo, A., Lupoli, R., Ambrosino, P., Di Minno, A. and Tarantino, G. "Omega-3 fatty acids for the treatment of nonalcoholic fatty liver disease", World $J$ Gastroenterol., 18(41).5839-5847. 2012.

[53] Johnston, C. "Functional foods as modifiers of cardiovascular disease”, Am. J. Life style Med., 3 (1). 39S-43S. 2009.

[54] Patil, U.K., Saraf, S. and Dixit, VK. "Hypolipidemic activity of seeds of Cassia tora Linn”, J Ethnopharmacol., 90.249-252. 2004.

[55] Miller, N.E., La Ville, A. and Crook, D. "Direct evidence that reverse cholesterol transport is mediated by high-density lipoprotein in rabbit”, Nature, 314.109-111. 1985.

[56] Zhao, J., Sun, X.B., Ye, F. and Tian, W.X. "Suppression of fatty acid synthase, differentiation and lipid accumulation in adipocytes by curcumin”, Mol Cell Biochem., 351. 19-28. 2011.

[57] Ejaz, A., Wu, D., Kwan, P. and Meydani, M. "Curcumin inhibits adipogenesis in 3 T3-L1 adipocytes and angiogenesis and obesity in C57/BL mice”, J Nutr., 139. 919-25. 2009.

[58] Shao, W., Yu, Z., Chiang, Y., Yang, Y., Chai, T., Foltz, W., Lu, H., Fantus, G. and Jin, T. "Curcumin Prevents High Fat Diet Induced Insulin Resistance and Obesity via Attenuating Lipogenesis in Liver and Inflammatory Pathway in Adipocytes", PLOS ONE, 7(1). e28784. 2012.

[59] Wang, S., Moustaid-Moussa, N., Chenb, L., Moc, H., Shastri, A., Su, R., Bapat, P., Kwun, I. and Shen, C.L. "Novel insights of dietary polyphenols and obesity", Journal of Nutritional Biochemistry, 25.1-18. 2014.

[60] Mozaffarian, D. and Wu, J.H. "(n-3) fatty acids and cardiovascular health. are effects of EPA and DHA shared or complementary? ”, J Nutr., 142(3).614S-625S. 2012.

[61] Neschen, S., Moore, I., Regittnig, W., Yu, C.L., Wang, Y., Pypaert, M., Petersen, K.F. and Shulman, G.I. "Contrasting effects of fish oil and safflower oil on hepatic peroxisomal and tissue lipid content”, Am J Physiol Endocrinol Metab., 282. E395-E401. 2002.

[62] Escher, P. and Wahli, W. "Peroxisome proliferator-activated receptors: insight into multiple cellular functions”, Mutat Res., 448 121-138. 2000.

[63] Brown, M.S. and Goldstein, J.L. "The SREBP pathway: regulation of cholesterol metabolism by proteolysis of a membrane-bound transcription factor", Cell, 89. 331-340. 1977.

[64] Matsumoto, T., Terai, S., Oishi, T., Kuwashiro, S., Fujisawa, K., Yamamoto, N., Fujita, Y., Hamamoto, Y., Furutani-Seiki, M., Nishina, H. and Sakaida, I. "Medaka as a model for human nonalcoholic steatohepatitis. Dis Model Mech., 3.431-440. 2010.

[65] Schoonjans, K., Staels, B.and Auwerx, J. "Role of the peroxisome proliferator-activated receptor (PPAR) in mediating the effects of fibrates and fatty acids on gene expression”, J Lipid Res., 37. 90725. 1996.

[66] Harnafi, H., Caid, H.S., Bouanani, N.H., Aziz, M. and Amrani, S. "Hypolipemic activity of polyphenol-rich extracts from Ocimum basilicum in Triton WR-1339-induced hyperlipidemic mice", Food Chem., 108. 205-212. 2008.

[67] Iqbal, K., Khan, A. and Khattak, M.A. "Biological significance of ascorbic acid (Vit. C) in human health, a review", Pakistan Journal of Nutrition, 3 (1). 5-13. 2004.

[68] Popescu, L.A., Vîrgolici, B., Lixandru, D., Miricescu, D., Condrut, E., Timnea, O., Ranetti, A.E., Militaru, M., Mohora, M. and Zăgrean, L. "Effect of diet and omega-3 fatty acids in NAFLD", Rom J Morphol Embryol., 54(3).785-90. 2013. 